\title{
Eficiência de uso da radiação solar na produtividade do trigo decorrente da adubação nitrogenada
}

\author{
Alexandre B. Heinemann ${ }^{1}$, Luís F. Stone ${ }^{1}$, Agostinho D. Didonet ${ }^{1}$, Maria da G. Trindade ${ }^{2}$, \\ Bruno B. Soares ${ }^{3}$, José A. A. Moreira ${ }^{1} \&$ Abelardo D. Cánovas ${ }^{1}$
}

\begin{abstract}
RESUMO
Visando avaliar os efeitos de doses de nitrogênio na eficiência do uso da radiação solar, índice de área foliar na antese, biomassa na antese, na maturação fisiológica e na produção de grãos de trigo de duas cultivares, conduziu-se um experimento na Embrapa Arroz e Feijão, em Santo Antônio de Goiás, GO, em plantio direto na palhada da cultura da soja. O delineamento experimental foi o de blocos ao acaso, com parcelas subdivididas e quatro repetições. Nas parcelas estabeleceram-se cinco doses de nitrogênio em cobertura, 0, 50, 100, 150 e $200 \mathrm{~kg} \mathrm{ha}^{-1}$ e, nas subparcelas, as cultivares Embrapa 22 e Embrapa 42. As cultivares diferiram apenas quanto à biomassa na antese. As variáveis estimadas apresentaram resposta quadrática às doses de N. A resposta da produção de grãos de trigo ao nitrogênio foi devida ao efeito deste nutriente no índice de área foliar que, por sua vez, afetou a eficiência de uso da radiação solar e a biomassa, que se correlacionaram positivamente com a produção. Sob baixa disponibilidade de nitrogênio, a produção de grãos de trigo apresentou maior correlação com a biomassa acumulada na antese que com aquela acumulada na maturação fisiológica.
\end{abstract}

Palavras-chave: Triticum aestivum, plantio direto, antese, maturação fisiológica

\section{Solar radiation use efficiency on the wheat grain yield as a function of nitrogen fertilizer}

\begin{abstract}
An experiment was carried out at Embrapa Rice and Beans, Santo Antônio de Goiás, Goiás State, Brazil, under no-tillage in the soybean mulch to evaluate the effects of nitrogen doses on the solar radiation use efficiency, leaf area index in the anthesis, biomass in the anthesis, in the physiological maturation and grain yield of two wheat cultivars. A randomized block design in subdivided plots, with four replications was used. In the plots five nitrogen topdressing doses, 0, 50, 100, 150, and $200 \mathrm{~kg} \mathrm{ha}^{-1}$ were established and in the subplots, the cultivars Embrapa 22 and Embrapa 42. The cultivars differed only in relation to biomass in anthesis. The analyzed variables showed a quadratic response to nitrogen doses. Wheat grain yield response to nitrogen was due to the effect of this nutrient in the leaf area index, that affected solar radiation use efficiency and biomass, which showed a positive correlation with grain yield. Under low nitrogen availability, grain yield showed higher correlation to biomass accumulated in the anthesis than to that accumulated in the physiological maturation.
\end{abstract}

Key words: Triticum aestivum, no-tillage, anthesis, maturation

1 Embrapa Arroz e Feijão, CP. 179, CEP 75375-000, Santo Antônio de Goiás, GO. Fone: (62) 3533-2104. E-mail: alexbh@cnpaf.embrapa.br; stone@cnpaf.embrapa.br; didonet@cnpaf.embrapa.br; jaloisio@cnpaf.embrapa.br; canovas@cnpaf.embrapa.br

${ }^{2}$ Embrapa Trigo/Núcleo Centro-Oeste. CP. 179, CEP 75375-000, Santo Antônio de Goiás, GO. Fone: (62) 3533-2152. E-mail: mgloria@cnpaf.embrapa.br

${ }^{3}$ Estudante de graduação da UFG, Bolsista da Embrapa Arroz e Feijão/SECTEC/CNPq. CP. 179, CEP 75375-000, Santo Antônio de Goiás, GO. Fone: (62) 3533-2171 


\section{INTRODUÇÃO}

No trigo, o número de flores por espigueta e o de espiguetas por espiga depende de fatores nutricionais e ambientais, além de fatores inerentes à própria cultivar (Aude et al., 1994). A maior disponibilidade de assimilados próximos a antese pode representar mais flores férteis e, conseqüentemente, grãos em maior número e tamanho, com maior capacidade de formar grãos cheios (Rodrigues, 2000; Silva et al., 2003). O trigo é altamente eficiente em remobilizar assimilados armazenados na pré-antese. De cada grama de assimilados armazenados, cerca de 0,68-0,78 g é remobilizado para a produção de biomassa do grão (Kiniry, 1993; Gebbing et al., 1999).

A partir do momento em que o óvulo é fecundado, ocorre intensa divisão celular. Somente após esta fase é que se iniciam a deposição de fotossintatos nas células do endosperma e o desenvolvimento das estruturas do embrião (Aude et al., 1994); neste momento, a área foliar verde exerce grande importância como tecido fotossintetizante ativo, proporcionando maior partição dos assimilados no enchimento do grão (Silva et al., 2003).

A produção de biomassa pelas culturas está relacionada à quantidade de radiação fotossinteticamente ativa, interceptada e absorvida pelas folhas, e à eficiência com que estas convertem a energia radiante em energia química, pela fotossíntese. Caviglia \& Sadras (2001) verificaram, em trigo, que a deficiência de nitrogênio reduziu a interceptação da luz devido à redução no índice de área foliar, parcialmente associada à redução no perfilhamento, causando redução na eficiência de uso da radiação solar. O aumento da produção de grãos de trigo com a adubação nitrogenada foi mais associado ao aumento da biomassa que ao índice de colheita. De fato, como as modernas cultivares de trigo já alcançaram índices de colheita bem próximos do limite teórico, o aumento de produção de grão deverá ser obtido pelo aumento na produção de biomassa, mantendo os presentes valores de partição da mesma (Calderini et al., 1997). Assim, qualquer fator que altere a eficiência de uso da radiação solar pode influenciar a produção de grãos de trigo.

Objetivou-se, com este trabalho, avaliar os efeitos de doses de nitrogênio aplicadas em cobertura na eficiência de uso da radiação solar, índice de área foliar, biomassa e produção de grão de duas cultivares de trigo, na região do Cerrado.

\section{MATERIAL E MÉTODOS}

Um experimento com a cultura do trigo irrigado foi conduzido na Embrapa Arroz e Feijão, localizada no município de Santo Antônio de Goiás, GO, latitude $16^{\circ} 28$ ' S, longitude $49^{\circ} 17^{\prime} \mathrm{W}$ e altitude de $824 \mathrm{~m}$, cujos dados climáticos observados durante o período de condução do experimento estão ilustrados na Figura 1. O solo da área experimental é classificado como Latossolo Vermelho distrófico, de textura argilosa. Os resultados da análise química do solo obtidos antes do início dos experimentos encontram-se na Tabela 1.

A irrigação foi efetuada por meio um sistema convencional de aspersão, conduzida de maneira que o seu reinício ocorria quando uma bateria de tensiômetros instalados a 0,15 m de profundidade acusava a tensão matricial de $40 \mathrm{kPa}$. Durante o período total de duração do experimento foram aplicados 477,2 mm de água.

O delineamento experimental foi o de blocos ao acaso, com parcelas subdivididas e quatro repetições. Nas parcelas, estabeleceram-se cinco doses de nitrogênio em cobertura, 0 , 50, 100, 150 e $200 \mathrm{~kg} \mathrm{ha}^{-1}$ e, nas subparcelas, duas cultivares de trigo, Embrapa 22 e Embrapa 42. A área das subparcelas foi de $6 \mathrm{~m}^{2}$.

A semeadura foi realizada em 16/5/2003, utilizando-se o sistema plantio direto. A cultura anterior, soja, deixou uma quantidade de resíduo de $1.857 \mathrm{~kg} \mathrm{ha}^{-1}$. A densidade de semeadura foi de 350 sementes aptas por $\mathrm{m}^{2}$, com espaçamento de $0,20 \mathrm{~m}$ nas entrelinhas. Antes da semeadura foi aplicado calcário dolomítico na proporção de $10 \mathrm{t} \mathrm{ha-1}$, sendo que na adubação de semeadura se aplicou a formulação 430-16 na dose de $400 \mathrm{~kg} \mathrm{ha}^{-1}$. Realizou-se a adubação de cobertura aplicando-se uréia, a lanço, em duas etapas: no

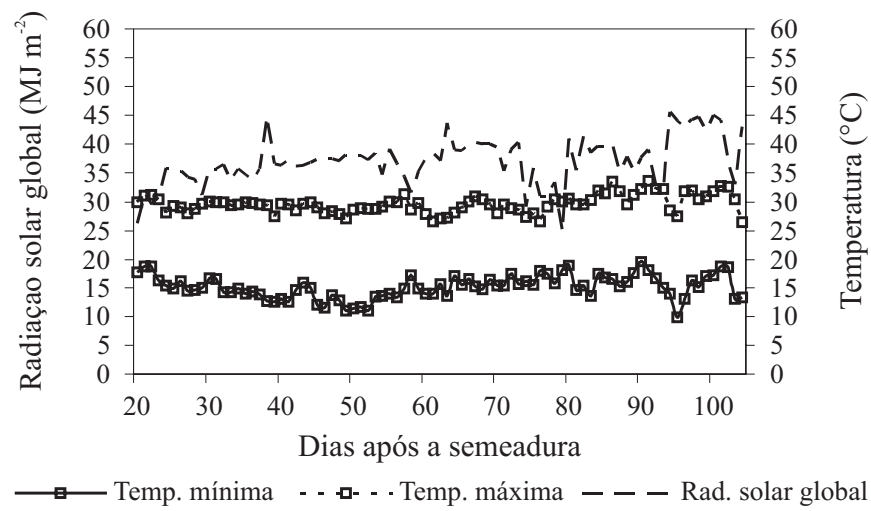

Figura 1. Dados diários de radiação solar e temperaturas máxima e mínima, durante o experimento

Tabela 1. Resultados da análise química do Latossolo Vermelho distrófico da área experimental(1)

\begin{tabular}{|c|c|c|c|c|c|c|c|c|c|c|c|c|}
\hline \multirow{2}{*}{$\begin{array}{c}\text { Camada } \\
\text { (cm) }\end{array}$} & \multirow{2}{*}{$\underset{\text { água }}{\mathrm{pH}}$} & $\mathrm{Ca}$ & $\mathrm{Mg}$ & Al & $\mathrm{H}+\mathrm{Al}$ & $P$ & $K$ & $\mathrm{Cu}$ & $\mathrm{Zn}$ & $\mathrm{Fe}$ & $M n$ & \multirow{2}{*}{$\begin{array}{c}\text { M.O. } \\
\mathrm{g} \mathrm{dm}^{-3}\end{array}$} \\
\hline & & \multicolumn{4}{|c|}{$\mathrm{mmol}_{\mathrm{c}} \mathrm{dm}^{-3}$} & \multicolumn{6}{|c|}{$\mathrm{mg} \mathrm{dm}^{-3}$} & \\
\hline $0-10$ & 6,5 & 40,5 & 15,4 & 0 & 38 & 7,2 & 161 & 5,0 & 1,7 & 45 & 57 & 16 \\
\hline $10-20$ & 6,1 & 26,1 & 9,6 & 0 & 40 & 4,3 & 81 & 5,3 & 1,4 & 38 & 39 & 14 \\
\hline $20-40$ & 5,3 & 8,1 & 3,3 & 2 & 56 & 0,9 & 75 & 4,7 & 0,8 & 49 & 25 & 12 \\
\hline $40-60$ & 5,5 & 11,7 & 4,0 & 1 & 33 & 0,4 & 53 & 4,1 & 0,3 & 44 & 20 & 10 \\
\hline $60-80$ & 5,7 & 9,0 & 3,2 & 0 & 24 & 0,1 & 34 & 3,8 & 0,3 & 38 & 14 & 6 \\
\hline
\end{tabular}

(1) Análise realizada no laboratório de solos do CNPAF 
início do estádio de perfilhamento, correspondente a 15 dias após a emergência do trigo, escala de Feeks 1, segundo Large (1954), e 15 dias depois (escala de Feeks 3), conforme os tratamentos adotados.

A área foliar foi medida aos 13 dias após a emergência (DAE) (escala de Feeks 1), no estádio de terceira folha expandida, aos 55 DAE, na antese (escala de Feeks 10), e aos 99 DAE, na maturação fisiológica (Escala de Feeks 11), em uma amostra de $0,10 \mathrm{~m}^{2}$ por subparcela, utilizando-se o medidor de área foliar LI 3100, LI-COR, NE, USA. A biomassa foi medida nos mesmos três estádios e nas mesmas amostras, após secagem em estufa a $70{ }^{\circ} \mathrm{C}$ por $72 \mathrm{~h}$.

A radiação fotossinteticamente ativa (RFA, 400 - $700 \mathrm{~nm}$ ) foi medida entre as linhas da cultura e no topo do dossel, em todas as subparcelas, nos estádios de terceira folha expandida e antese, com o auxílio de um monitor solar marca LI-COR, modelo LI 1776, e um sensor marca LI-COR, modelo LI 191SB Line Quantum, em que as leituras foram feitas entre 13 e 14 h. A fração da radiação fotossinteticamente ativa interceptada pelo dossel da cultura (RFAi) foi, então, calculada e transformada em $\mathrm{MJ} \mathrm{m}^{-2} \mathrm{~d}^{-1}$, assumindo-se que a RFA corresponde a $50 \%$ da radiação solar global diária incidente média, no período compreendido entre os dois estádios. A radiação solar global foi medida na estação meteorológica da Embrapa Arroz e Feijão, situada a cerca de 1 km da área experimental.

Determinou-se a taxa de incremento da biomassa, expressa em $\mathrm{g} \mathrm{m}^{-2} \mathrm{dia}^{-1}$, entre os estádios de terceira folha expandida e antese e, a seguir, foi calculada a eficiência de uso da radiação solar (EUR), em g $\mathrm{MJ}^{-1}$. Por outro lado, a produção de grãos foi determinada nas três linhas centrais da subparcela, em uma área útil de $3 \mathrm{~m}^{2}$.

Foram feitas análises de variância e de regressão das variáveis eficiência de uso da radiação, índice de área foliar medido na antese, biomassa medida no mesmo estádio e na maturação fisiológica e produção de grãos, utilizando-se o software SAS 8.2.

\section{RESULTADOS E DISCUSSÃO}

As cultivares não diferiram significativamente em relação à eficiência de uso da radiação solar, no período anterior à antese (Tabela 2), possivelmente porque as cultivares não diferem quanto ao índice de perfilhamento, ciclo e altura das plantas (Reis et al., 1999; Cánovas \& Só e Silva, 2002). A EUR variou de $0,68 \mathrm{~g} \mathrm{MJ}^{-1}$, na ausência de adubação nitrogenada em cobertura, até o valor máximo estimado de 1,19 g MJ$^{-1}$, obtido com 160,0 kg ha-1 (Figura 2A). Caviglia \& Sadras (2001) obtiveram, na Argentina, valores médios de EUR variando de $0,85 \mathrm{~g} \mathrm{MJ}^{-1}$, na ausência de nitrogênio, a 1,07 g MJ-1, com adubação nitrogenada. Delden (2001) verificou que a limitação de nitrogênio causou decréscimo na RFAi acumulada, enquanto a deficiência de nitrogênio em trigo reduz o índice de área foliar e, em conseqüência diminui a superfície de interceptação de luz, conforme observaram Caviglia \& Sadras (2001). De fato, o índice de área foliar na antese respondeu de maneira quadrática à adubação nitrogenada em cobertura, sendo o valor máximo de $\mathrm{N}$ estimado igual a $164,2 \mathrm{~kg} \mathrm{ha}^{-1}$ (Figura 2B), e apresentou correlação positiva e altamente significativa com a eficiência de uso da radiação solar (Tabela 3). As cultivares não diferiram significativamente em relação ao IAF (Tabela 2).

Apesar das cultivares não diferirem significativamente quanto à eficiência de uso da radiação solar na pré-antese e ao índice de área foliar na antese, elas diferiram quanto à biomassa acumulada neste último estádio (Tabela 2), tendo a cultivar Embrapa 42 acumulado mais biomassa que a Embrapa 22. A biomassa acumulada das duas cultivares respondeu de maneira quadrática às doses de nitrogênio (Figura 2C), sendo os maiores valores estimados obtidos com as doses de $\mathrm{N}$ de 137,3 e 132,4 $\mathrm{kg} \mathrm{ha}^{-1}$, respectivamente, para as cultivares Embrapa 22 e Embrapa 42. A resposta

Tabela 3. Valores do coeficiente de correlação ${ }^{1}$ de Pearson ( $r$ ) entre as variáveis analisadas

\begin{tabular}{|c|c|c|c|c|}
\hline \multirow{3}{*}{ Variável } & & Bio & assa & \multirow{3}{*}{$\begin{array}{l}\text { Produção } \\
\text { de grãos } \\
\left(\mathrm{kg} \mathrm{ha}^{-1}\right)\end{array}$} \\
\hline & $\begin{array}{c}\text { TAF' } \\
\left(\mathrm{m}^{2} \mathrm{~m}^{-2}\right)\end{array}$ & $\begin{array}{c}\text { Antese } \\
\left(\mathrm{kg} \mathrm{ha}^{-1}\right)\end{array}$ & $\begin{array}{c}\text { Maturação } \\
\left(\mathrm{kg} \mathrm{ha}^{-1}\right)\end{array}$ & \\
\hline & \multicolumn{3}{|c|}{ Coeficiente de correlação } & \\
\hline $\operatorname{EUR}^{3}\left(\mathrm{~g} \mathrm{MJ}^{-1}\right)$ & $0,50^{\star *}$ & $0,53 * \star$ & 0,31 * & $0,36^{*}$ \\
\hline IAF $\left(m^{2} m^{-2}\right)$ & - & 0,64 ** & $0,41 * \star$ & $0,55^{\star \star}$ \\
\hline $\begin{array}{l}\text { Biomassa na antese } \\
\left(\mathrm{kg} \mathrm{ha}^{-1}\right)\end{array}$ & - & - & $0,46^{\star *}$ & $0,51^{* *}$ \\
\hline $\begin{array}{l}\text { Biomassa na maturação } \\
\left(\mathrm{kg} \mathrm{ha}^{-1}\right)\end{array}$ & - & - & - & $0,26^{+}$ \\
\hline
\end{tabular}

Tabela 2. Resumo da análise de variância

\begin{tabular}{lcccccc}
\hline \multirow{2}{*}{ Fonte de variação } & G.L. & \multicolumn{5}{c}{ Quadrado Médio } \\
\cline { 3 - 7 } Bloco & 3 & EUR $^{1}$ & IAF & Biomassa na antese & Biomassa na maturação & Produção de grãos \\
\hline Nitrogênio (N) & 4 & $0,012^{\text {ns }}$ & $0,548^{\text {ns }}$ & $773595^{\text {ns }}$ & $4881602^{\text {ns }}$ & $1039102^{\text {ns }}$ \\
Erro a & 12 & $0,284^{*}$ & $19,316^{* *}$ & $16053963^{* *}$ & $12206636^{*}$ & $6438918^{*}$ \\
Cultivar (C) & 1 & 0,064 & 0,532 & 1119010 & 4103147 & 1259748 \\
N x C & 4 & $0,002^{\text {ns }}$ & $1,332^{\text {ns }}$ & $21352662^{* *}$ & $8848412^{\text {ns }}$ & $50084^{\text {ns }}$ \\
Erro b & 15 & $0,036^{\text {ns }}$ & $2,688^{\text {ns }}$ & $1497241^{\text {ns }}$ & $3705957^{\text {ns }}$ & $382325^{\text {ns }}$ \\
\hline
\end{tabular}

1EUR:- Eficiência de uso da radiação solar entre 0 estádio de três folhas e a antese; ${ }^{2} \mathrm{AF}:$ Índice de área foliar na antese

EUUR:- Eficiência de uso da radiação solar entre o estádio de três folhas e a antese; ${ }^{2}$ IAF: Indice de
$n$ ns, ${ }^{*},{ }^{* *}$ : Respectivamente não significativo e significativo a 1 e $5 \%$ de probabilidade pelo teste $\mathrm{F}$ 
ao nitrogênio foi devida ao efeito deste nutriente no índice de área foliar e na eficiência de uso da radiação solar, que apresentaram correlação positiva e altamente significativa com a biomassa na antese (Tabela 3).

Embora a cultura do trigo possa suportar algum grau de limitação, em função da redução da superfície de interceptação de luz, em condição de estresse, mesmo nos piores ambientes a massa da matéria seca dos grãos não muda na mesma proporção que as mudanças impostas na superfície de interceptação de luz, ou seja, a massa da matéria seca dos grãos responde marginalmente a mudanças ocorridas na fotossíntese durante seu enchimento (Borrás et al., 2004). Isto se deve ao fato de que, em condições de estresse, os assimilados armazenados antes do início do enchimento dos grãos podem contribuir com mais de 50\% da sua massa final (Gent, 1994). Assim, a maior disponibilidade de assimilados próximos à antese pode representar mais flores férteis e, conseqüentemente, maior número e tamanho de grãos, com mais capacidade de formar grãos cheios (Rodrigues, 2000; Silva et al., 2003). De fato, observa-se, na Tabela 3, que a produção de grãos se correlacionou significativamente com a eficiência de uso da radiação, índice de área foliar e biomassa na antese. Nedel (1994) também verificou correlação entre a biomassa na antese e a produção de grãos do trigo.

Apesar das diferenças entre as cultivares com relação a biomassa na antese, elas não diferiram quanto a biomassa na maturação fisiológica (Tabela 2). A biomassa acumulada na maturação variou de 7869 kg ha-1, na ausência de adubação nitrogenada em cobertura, até o valor máximo estimado de $10.767 \mathrm{~kg} \mathrm{ha}^{-1}$, obtido com a dose de $\mathrm{N}$ de $119,4 \mathrm{~kg} \mathrm{ha}^{-1}$ (Figura 2D). Caviglia \& Sadras (2001) obtiveram valores médios de biomassa variando de $6.350 \mathrm{~kg} \mathrm{ha}^{-1}$, na ausência de nitrogênio, a $12.420 \mathrm{~kg} \mathrm{ha}^{-1}$, com adubação nitrogenada. Coelho et al. (1998) verificaram valores de biomassa na maturação da cultivar Embrapa 22, variando de 8.828-10.096 kg ha-1, na ausência de adubação nitrogenada em cobertura, a 10.616$13.040 \mathrm{~kg} \mathrm{ha}^{-1}$, com adubação nitrogenada.

A biomassa na maturação correlacionou-se positiva e significativamente com as demais variáveis analisadas (Tabela 3). Sua correlação com a produção de grãos foi menos significativa que a desta com a biomassa na antese; isto se deve, provavelmente, pela alta eficiência do trigo em remobilizar assimilados armazenados na pré-antese e usá-los para o crescimento dos grãos (Kiniry, 1993; Gebbing et al., 1999), sendo muito importante para a produção de grãos, em condições de estresse, a biomassa desenvolvida até a antese. Nedel (1994) também constatou correlação positiva entre biomassa na maturação e produção de grãos.

As cultivares não diferiram quanto à produção de grãos (Tabela 2), apresentando resposta quadrática ao nitrogênio, sendo a produção de grãos máxima estimada de $6.472 \mathrm{~kg} \mathrm{ha}^{-1}$ obtida com a dose de $\mathrm{N}$ de 156,1 kg ha-1 (Figura 2E). Como comentado anteriormente, esta resposta foi devida a influência do nitrogênio no índice de área foliar que, por sua vez, afetou a eficiência de uso da radiação solar e a biomassa, que se correlacionaram positivamente com a produção de grãos. As produções obtidas estão próximas dos valores encontrados por Coelho et al. (1998) para a cultivar Embrapa 22, que
A.

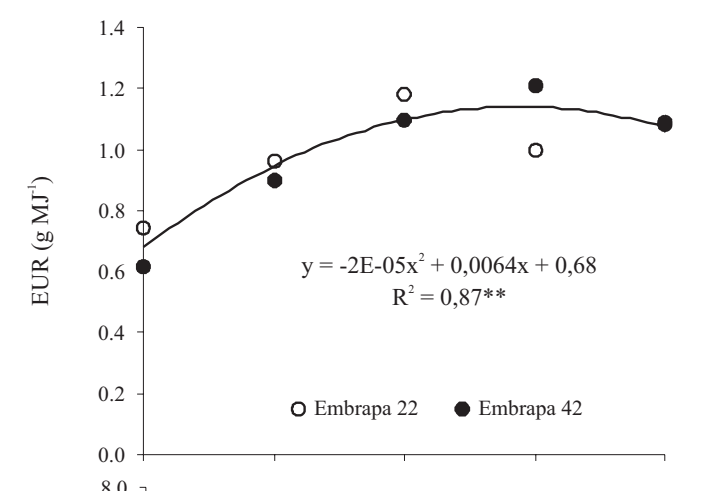

B.

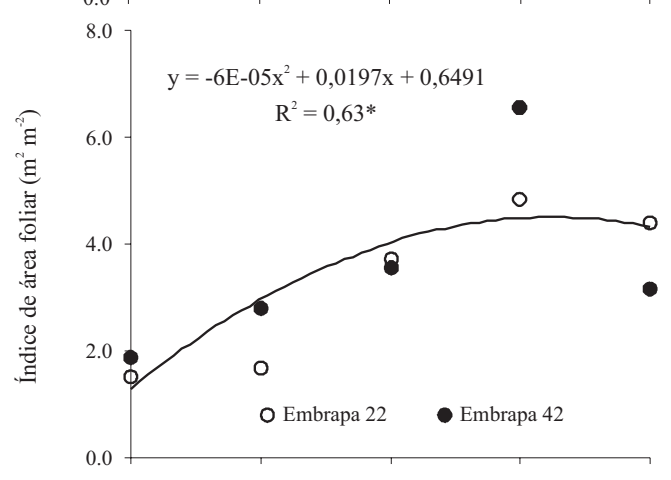

C.

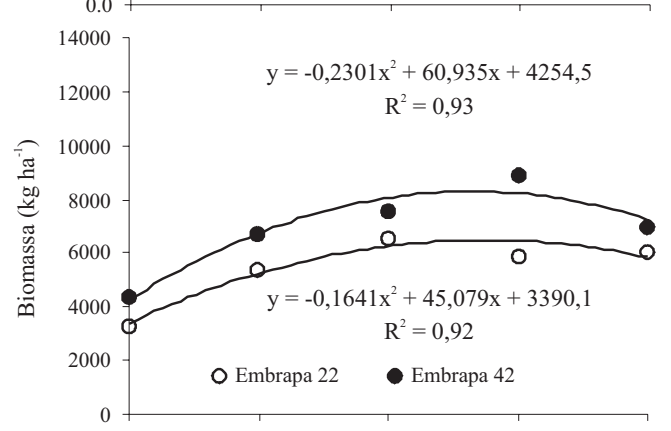

D.

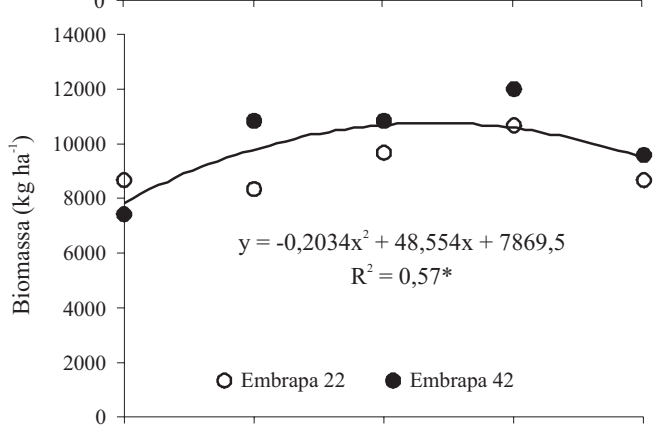

E.

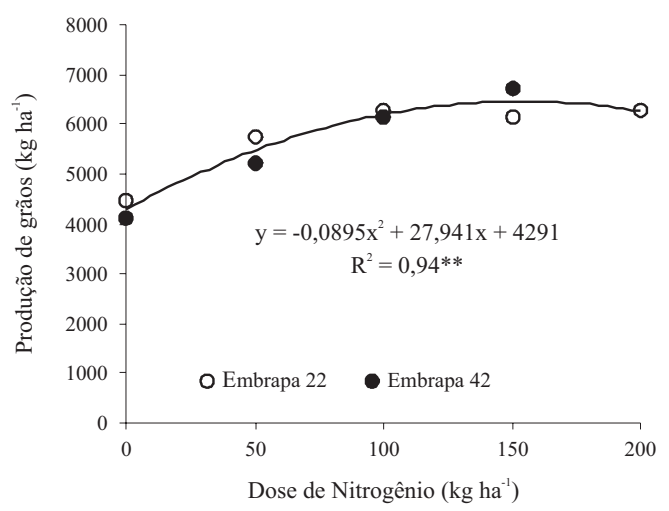

Figura 2. Efeito de doses crescentes de nitrogênio aplicadas em cobertura nas cultivares de trigo Embrapa 22 e Embrapa 42; (A) na eficiência média de uso da radiação solar (EUR) entre os estádios de terceira folha expandida e antese; (B) no índice de área foliar médio, na antese; (C) na biomassa, na antese; (D) na biomassa, na maturação fisiológica e (E) na produção de grãos de trigo 
variaram de $3.981 \mathrm{~kg} \mathrm{ha}^{-1}$, na ausência de adubação nitrogenada em cobertura, a $5.840 \mathrm{~kg} \mathrm{ha}^{-1}$, com adubação nitrogenada.

\section{CONCLUSÕES}

1. A resposta da produção de grãos de trigo ao nitrogênio foi devida a influência deste nutriente no índice de área foliar que, por sua vez, afetou a eficiência de uso da radiação solar e a biomassa, que se correlacionaram positivamente com a produção.

2. Sob baixa disponibilidade de nitrogênio, a produção de grãos apresentou maior correlação com a biomassa acumulada na antese que com aquela acumulada na maturação fisiológica.

\section{LITERATURA CITADA}

Aude, M. I. da S.; Marchezan, E.; Mairesse, L. A. da S.; Bisognin, D. A.; Cima, R. J.; Zanini, W. Taxa de acúmulo de matéria seca e duração do período de enchimento de grão do trigo. Pesquisa Agropecuária Brasileira, Brasília, v.29, n.10, p.15331539, 1994.

Borrás, L.; Slafer, G. A.; Otegui, M. E. Seed dry weight response to source-sink manipulations in wheat, maize and soybean: a quantitative reappraisal. Field Crops Research, Amsterdam, v.86, n.1, p.131-146, 2004.

Calderini, D. F.; Dreccer, M. F.; Slafer, G. A. Consequences of breeding on biomass, radiation interception and radiation-use efficiency in wheat. Field Crops Research, Amsterdam, v.52, n.3, p.271-281, 1997.

Cánovas, A. D.; Silva, M. S. Avaliação de ensaios de cultivares e linhagens de trigo de sequeiro e irrigado na Embrapa Arroz e Feijão - 2000. In: Reunião da Comissão Centro Brasileira de Pesquisa de Trigo, 11, 2000, Rio Verde. Resumos Expandidos... Rio Verde: FESURV, 2002. p.60-63.
Caviglia, O. P.; Sadras, V. O. Effect of nitrogen supply on crop conductance, water- and radiation-use efficiency of wheat. Field Crops Research, Amsterdam, v.69, n.3, p.259-266, 2001.

Coelho, M. A. O.; Souza, M. A.; Sediyama, T.; Ribeiro, A. C.; Sediyama, C. S. Resposta da produtividade de grãos e outras características agronômicas do trigo Embrapa-22 irrigado ao nitrogênio em cobertura. Revista Brasileira de Ciência do Solo, Viçosa, v.22, n.3, p.555-561, 1998.

Delden, A. van. Yield and growth components of potato and wheat under organic nitrogen management. Agronomy Journal, Madison, v.93, n.6, p.1370-1385, 2001.

Gebbing, T.; Schnyder, H.; Kurhbauch, W. The utilization of preanthesis reserves in grain filling of wheat. Assessment by steady state ${ }^{13} \mathrm{CO}_{2} /{ }^{12} \mathrm{CO}_{2}$ labeling. Plant Cell and Environment, Oxford, v.22, n.7, p.851-858, 1999.

Gent, M. P. N. Photosynthate reserves during grain filling in winter wheat. Agronomy Journal, Madison, v.86, p.159-167, 1994.

Kiniry, J. R. Nonstructural carbohydrate utilization by wheat shaded during grain growth. Agronomy Journal, Madison, v.85, p.844-849, 1993.

Large, E. C. Growth stages in cereals. Illustration of the Feeks scale. Plant Pathology, v.3, p.128-129, 1954.

Nedel, J. L. Progresso genético no rendimento de grãos de cultivares de trigo lançadas para cultivo entre 1940 e 1992. Pesquisa Agropecuária Brasileira, Brasília, v.29, n.10, p.1565-1570, 1994.

Reis, W. P.; Vello, N. A.; Ferreira, D. F.; Ramalho, M. A. P. Associação entre coeficiente de parentesco e técnicas multivariadas, como medidas de divergência genética de cultivares de trigo. Ciência e Agrotecnologia, Lavras, v.23, n.2, p.258-269, 1999.

Rodrigues, O. Manejo de trigo: bases ecofisiológicas. In: Cunha, G. R.; Bacaltchuk, B. Tecnologia para produzir trigo no Rio Grande do Sul. Porto Alegre: Assembléia Legislativa do Rio Grande do Sul, 2000. p.120-169. Série Culturas - Trigo

Silva, S. A.; Carvalho, F. I. F. de; Nedel, J. L.; Cruz, P. J.; Peske, S. T.; Simioni, D.; Cargnin, A. Enchimento de sementes em linhas quase-isogênicas de trigo com presença e ausência do caráter "stay-green”. Pesquisa Agropecuária Brasileira, Brasília, v.38, n.5, p.613-618, 2003. 